\title{
Observation evidences of atmospheric Gravity Waves induced by seismic activity from analysis of subionospheric LF signal spectra
}

\author{
A. Rozhnoi ${ }^{1}$, M. Solovieva ${ }^{1}$, O. Molchanov ${ }^{1}$, P.-F. Biagi ${ }^{2}$, and M. Hayakawa ${ }^{3}$ \\ ${ }^{1}$ Institute of the Earth Physics, RAS, Bolshaya Gruzinskaya 10, Moscow, Russia \\ ${ }^{2}$ University of Bari, Bari, Italy \\ ${ }^{3}$ University of Electro-Communications, Chofu, Tokyo, Japan
}

Received: 18 July 2007 - Revised: 28 September 2007 - Accepted: 3 October 2007 - Published: 26 October 2007

\begin{abstract}
We analyze variations of the LF subionospheric signal amplitude and phase from JJY transmitter in Japan $(\mathrm{F}=40 \mathrm{kHz})$ received in Petropavlovsk-Kamchatsky station during seismically quiet and active periods including also periods of magnetic storms. After $20 \mathrm{~s}$ averaging, the frequency range of the analysis is $0.28-15 \mathrm{mHz}$ that corresponds to the period range from 1 to $60 \mathrm{~min}$. Changes in spectra of the LF signal perturbations are found several days before and after three large earthquakes, which happened in November $2004(M=7.1)$, August $2005(M=7.2)$ and November 2006 $(\mathrm{M}=8.2)$ inside the Fresnel zone of the Japan-Kamchatka wavepath. Comparing the perturbed and background spectra we have found the evident increase in spectral range 10-25 min that is in the compliance with theoretical estimations on lithosphere-ionosphere coupling by the Atmospheric Gravity Waves ( $T>6 \mathrm{~min}$ ). Similar changes are not found for the periods of magnetic storms.
\end{abstract}

\section{Introduction}

Different ideas concerning the influence of acoustic and gravity waves upon the upper atmosphere in connection with seismicity have been pushed ahead rather long time ago (see Nekrasov et al., 1995; Gokhberg et al., 1995; Liperovsky et al., 2000 and references therein). For example, attention has been devoted to the direct coupling of precursory seismic oscillations near the Earth's eigenmodes (periods $\sim 1 \mathrm{~h}$ ) with the Atmospheric Gravity Waves (AGW) at the ground surface (Lin'kov et al., 1990; Garmash et al., 1989). However, it has been recognized only recently, that the source had a turbulent nature such as being sporadic in time and exhibiting spatial variations. This dictates a change of approach: instead of considering plane (or spherical) waves propagat-

Correspondence to: A. Rozhnoi

(rozhnoi@ifz.ru)

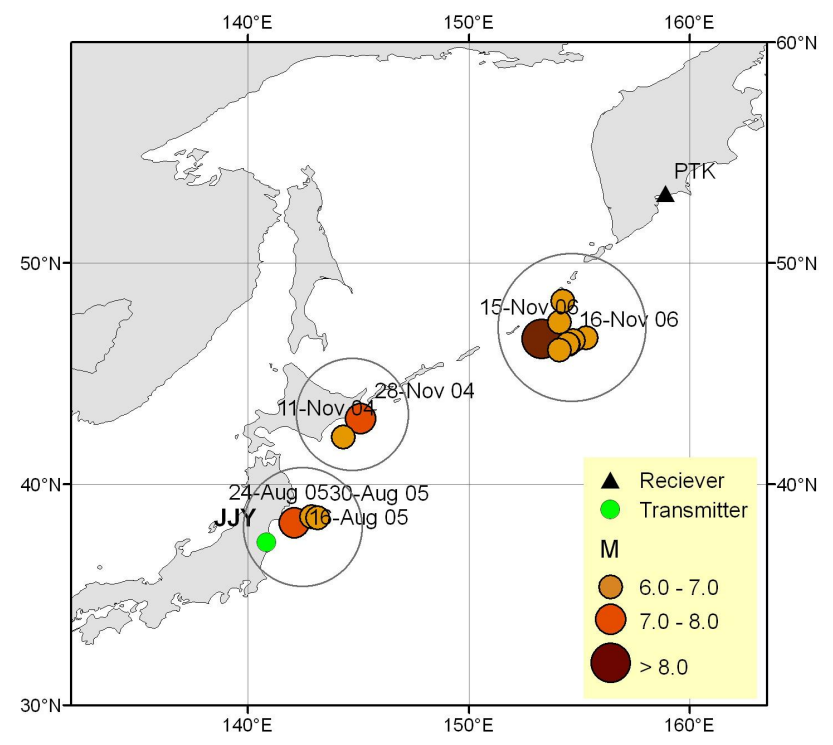

Fig. 1. Positions of the earthquake epicenters for 3 periods of strong seismic activity in 2004-2006.

ing with phase velocity, we need to expand our perturbation as a sum of pulses or structures (wavelets) propagating with group velocity. These two approaches could give more or less equivalent results in a case of isotropic propagation, like as for acoustic waves with frequencies $\omega>>\omega_{B}$, where $\omega_{B}$ is the Brunt-Vaisala frequency. However, the second approach is certainly preferable if one is interested in the propagation of perturbation energy by anisotropic waves like AGW in the range $\omega<\omega_{B}$ (period T $>6 \mathrm{~min}$ ). Propagation of AGW turbulent energy into the upper atmosphere/lower ionosphere was considered by Mareev et al. (2002), Molchanov (2004) and recently by Molchanov and Hayakawa (2007) in details.

Although the mechanism of the atmosphere-ionosphere coupling has been discussed theoretically in many works,

Published by Copernicus Publications on behalf of the European Geosciences Union. 


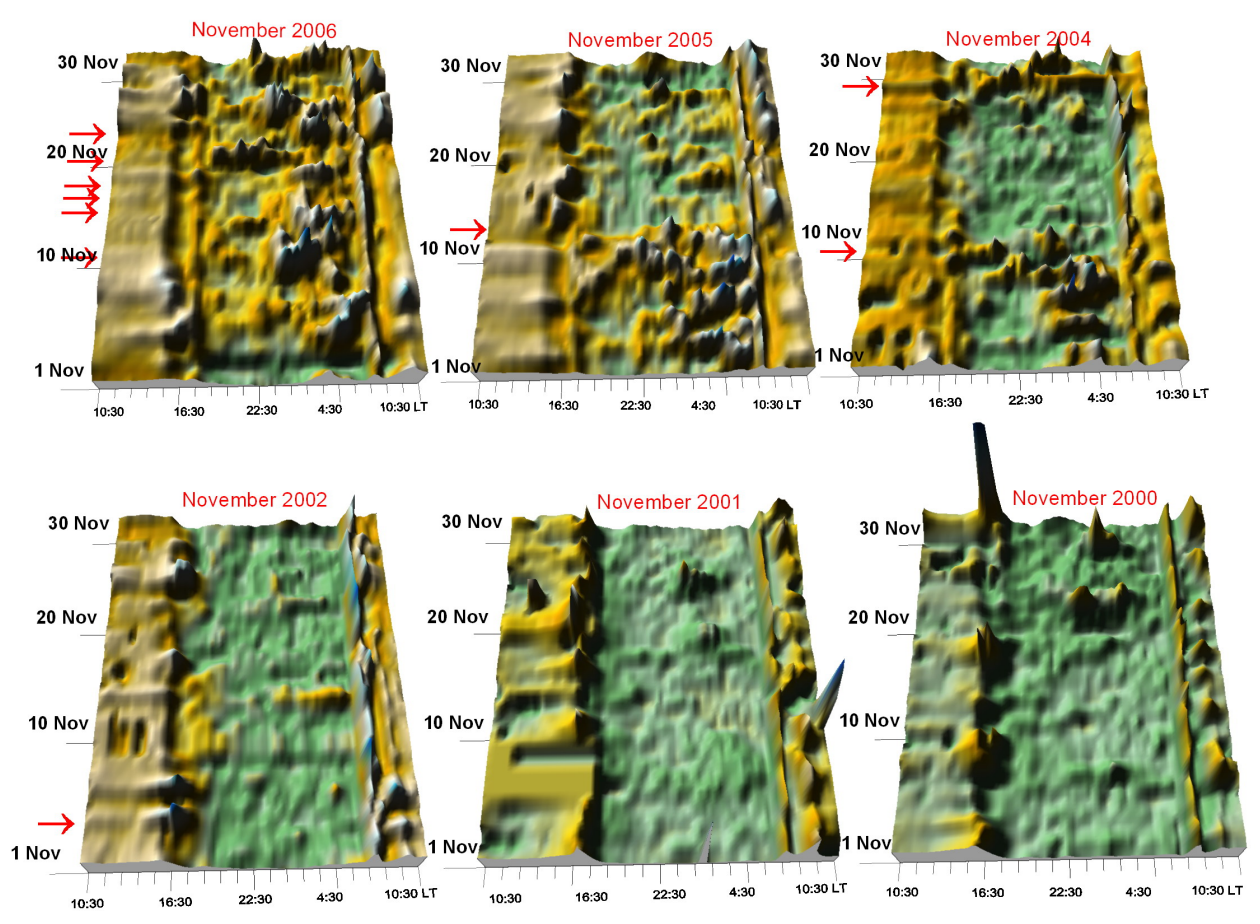

Fig. 2. 3-D image day-to-day sequences of the diurnal variations of the amplitude of LF signal for November, 2000, 2001, 2002, 2004, 2005 and 2006. Arrows indicate the date of the earthquakes with $\mathrm{M}>6$.

the experimental verifications of seismic-associated AGW are not numerous. Ionospheric perturbation was observed on satellites from the tsunami wave front generated by the Sumatra earthquake of 26 December 2004 (Lognonne et al., 2005). Such a perturbation was associated to the coupling between the gravity tsunami wave and atmospheric gravity waves and revealed a time delay of about $1 \mathrm{~h}$. During the period of seismic activity for the wave-path JJY- Chofu was found a maximum in a spectrum of the amplitude of LF signal in the range below $30 \mathrm{~min}$ and a small maximum at 12 min (Molchanov et al., 2001; Miyaki et al., 2002).

In this paper we present the further evidence of AGWs induced by seismic activity from the analysis of LF signal spectra.

\section{Observation and results}

We analyze variations of the subionospheric LF signal amplitude and phase from JJY transmitter in Japan $(F=40 \mathrm{kHz})$ received in Petropavlovsk-Kamchatsky station. The 20-s digital data of the signal are used. The observations during 20042006 have been included into examination. Three groups of the strongest earthquakes with $M>7$ which happened in this interval of time in the zone of sensitivity of our wave path (3 Fresnel zones) have been selected. The transmitter and receiver locations together with the distribution of earthquakes epicenters for the period 2004-2006 are shown in Fig. 1.
The first series of earthquakes occurred in November and December 2004 in Hokkaido region (Japan). Within almost 3 months until the first earthquake $(M=5.6,02.11 .04)$ there were no any strong earthquakes with $\mathrm{M}>5.0$ in this region. Night-time "bay-lake" phase and amplitude anomalies of the LF signal have begun 3-5 days before the first earthquake and continued up to the last earthquake of this set $(M=6.2$, 11 November 2004). Whereupon a period of seismic calm was observed within about a fortnight. Then there followed anomalies of the LF signal before two earthquakes ( $M=7.1$, 28.11.04 and $\mathrm{M}=6.8,6.12 .04)$. The next $\mathrm{LF}$ anomalies were observed before earthquakes December, 18 and 21 (M=5.8 and $M=5.6$ ). During the whole period of seismic activity a significant shift in terminator times was also evident (in detail Rozhnoi et al., 2005).

The second series of strong earthquakes happened near Honshu (Japan) area in August 2005 and consisted of 3 earthquakes: $\mathrm{M}=7.2,16.08 .05, \mathrm{M}=6.2,24.08 .05$, and $\mathrm{M}=6.2$, 30.08.05. Anomalies were observed on the amplitude and phase of the LF signal; they have started 2 days before the first earthquake and lasted during all the period of seismic activity (Rozhnoi et al., 2007).

At last, the very strong earthquake with $\mathrm{M}=8.3$ took place in Central Kuril region (Russia) in 15 November 2006. Following to this, a series of strong aftershocks $(M=5-6.5)$ was observed during several months. The monitoring of the LF signal was carried out within 15 days before and 15 days after the main shock. Anomalies of amplitude and phase of the 


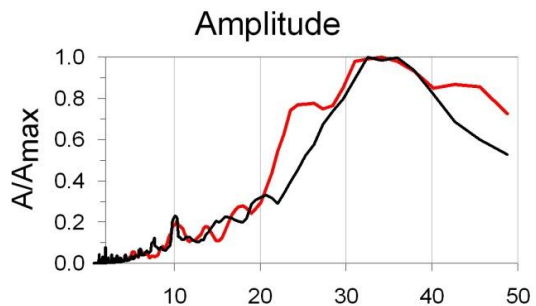

a)
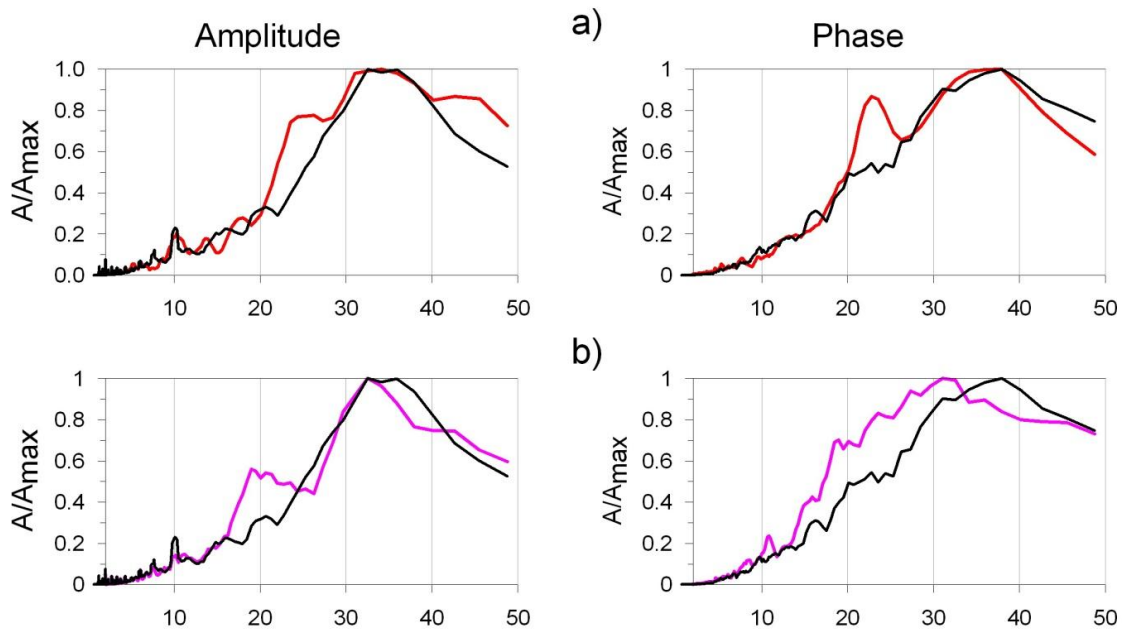

b)

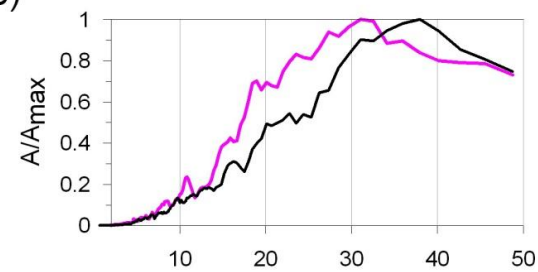

c)
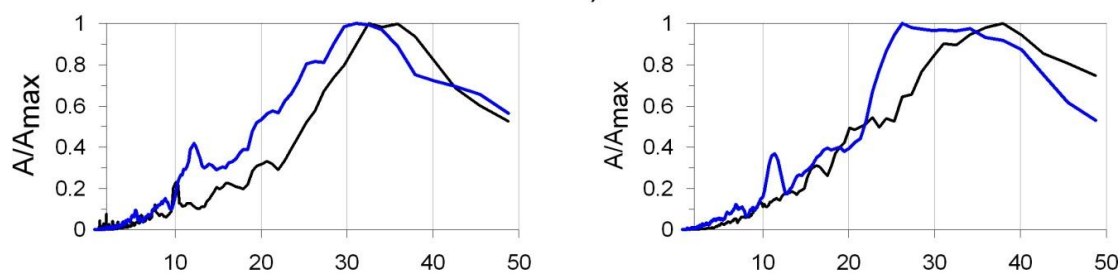

d)
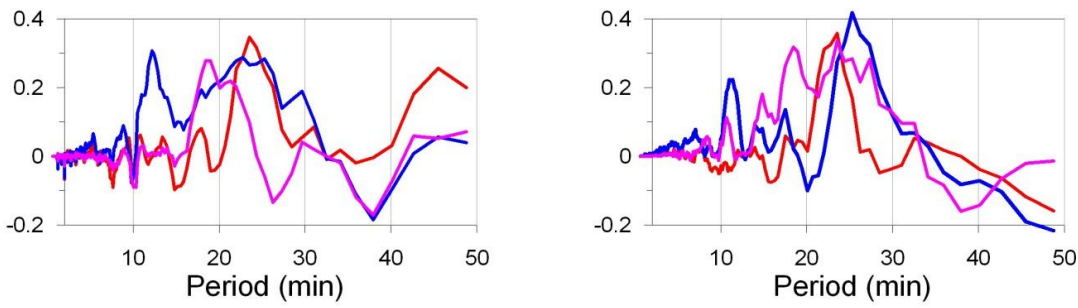

Fig. 3. Normalized spectra of amplitude (left panel) and phase (right panel) of the LF signal for three series of earthquakes. (a) NovemberDecember 2004 - red line; (b) August 2005 - pink line; (c) November 2006 - blue line. Black line - averaged spectrum of 19 quiet days. Differences in spectra density between seismically active and quiet days for three series of earthquakes are shown in panel (d). Colors of lines correspond to the colors on panels (a), (b), (c).

signal have begun about 10 days prior to the earthquake and were observed up to the end of November.

We have analyzed the signal during November for 6 years -2000-2006 except for 2003 when data were absent (Fig. 2). Only nighttime interval from 19:00 till 07:00 of local time was examined. Variations of the signal are insignificant in 2000 and 2001 when there were no earthquakes in the sensitivity zone of the wave path. Small disturbances in the signal (yellow color) are registered within several days in 2002 during and after an earthquake with $M=6.4$. Rather strong disturbances of the signal associated with earthquakes are clearly observed in 2004 and 2005. The longest and the strongest disturbances are obvious for the period of very strong seismic activity in 2006. From the analysis of these data we can conclude that the observed anomalies in the signal are caused by seismic activity.

In previous works we have applied the spectral analysis to several cases of seismically disturbed days (Rozhnoi et al., $2004,2005)$. It was found that the maximum of a spectrum had the period about $20-25 \mathrm{~min}(0.7-0.8 \mathrm{mHz})$.

In this work we demonstrate the accumulated spectra of the amplitude and phase of the signal for the 3 series of seismic activity described above. Only nighttime of the signal filtered in a frequency band of $0.28-15 \mathrm{MHz}$ that corresponds to the period range $\mathrm{T}$ from 1 to $60 \mathrm{~min}$ was used for spectral analysis. Days, where the filtered signal exceeded background more than $3 \sigma$ (except for magnetically disturbed days), have been included in consideration. The 
selected disturbances for each case included several days before the first quake in the series and anomalous days during all the period of seismic activity. Sometimes it was not clear whether these anomalies were connected with the preseismic perturbation related to the next quake or to the postseismic effect after the previous quake. Anyway we consider it as a manifestation of EQ influence on the upper atmospherelower ionosphere boundary that controls the signal properties. Thus $12-15$ seismically disturbed days have been selected in each case. For comparison the accumulated spectra of 19 days for quiet magnetic and seismic periods have been calculated.

The normalized summary spectra of anomaly days and quiet days for the all series are presented in Fig. 3 together with differential spectra (the difference between the summary spectra of anomaly and quiet days). Each spectrum is normalized by its own Amax.

Both spectra of quiet days and of anomaly days have the main maximum about 30-35 min, but in the spectra of seismo-induced anomaly days a second maximum with period $20-25 \mathrm{~min}$ is clearly observed for all the cases. Some more maxima in the shorter periods range (about 10-12 min) are also revealed for anomaly days. The frequency range of the signal corresponds to the AGW frequency (Miyaki et al., 2002).

As to magnetically disturbed days the shift in lower frequencies, typical for seismically disturbed days, is not revealed (Rozhnoi et al., 2005, 2006).

\section{Conclusions}

As it is mentioned in introduction, the thorough discussion of AGW seismo-associated influence upon ionosphere is presented in the book by Molchanov and Hayakawa (2007) including consideration of the source properties, AGW turbulence propagation into atmosphere, competition with natural atmospheric turbulence, and transformation in the plasma variations at the lower ionosphere. The observation results presented here are more or less in compliance with the theoretical approach. Note that we did not found any effect in the infrasound frequency range ( $\mathrm{T}=1-5 \mathrm{~min})$.

Acknowledgements. The work was supported by ISTC under Grant 2990.

Edited by: S. Tinti

Reviewed by: D. Trian and another anonymous referee

\section{References}

Garmash, S. V., Lin'kov, E. M., Petrova, L. N., and Shved, G. M.: Excitation of atmospheric oscillations of the Earth, Izv. Phys. Atmos. Ocean, 25, 1290-1299, 1989.
Gokhberg, M. B., Morgounov, V. A., and Pokhotelov, O. A.: Earthquake prediction: seismoelectromagnetic phenomena, Gordon and Breach Sci. Pub., 287 pp., 1995.

Lognonne, P., Jeansou, E., Garcia, R., Artru, J., Occhipinti, G., Crespon, F., Achache, J., Helbert, J., and Moreaux, G.: Detection of the Ionospheric perturbation associated to the tsunami of December 26th, 2004 with Topex and Jason-1 TEC data, Geophys. Res. Abstracts, 7, 09028, 2005.

Lin'kov, E. M., Petrova, L. N., and Osipov, K. S.: Seismogravity pulsations of the Earth and atmospheric disturbances as possible precursors of strong earthquakes, Doklady RAN, 313, 239-258, 1990.

Liperovsky, V. A., Pokhotelov, O. A., Liperovskaya, E. V., Parrot, M., Meister, C.-V., and Alimov, O. A.: Modification of sporadic E-layers caused by seismic activity, Surveys in Geophysics, 21, 449-486, 2000.

Miyaki, K., Hayakawa, M., and Molchanov, O. A.: The role of gravity waves in the lithosphere-ionosphere coupling, as revealed from the subionospheric LF propagation data, in: Seismo-Electromagnetics (Lithosphere-Atmosphere-Ionosphere Coupling), edited by: Hayakawa, M. and Molchanov, O., Terrapub, Tokyo, 229-232, 2002.

Mareev, E. A., Iudin, D. I., and Molchanov, O. A.: Mosaic source of internal gravity waves associated with seismic activity, in: Seismo- Electromagnetics (Lithosphere-Atmosphere-Ionosphere Coupling), edited by: Hayakawa, M. and Molchanov, O., Terrapub, Tokyo, 335-342, 2002.

Molchanov, O. A., Hayakawa, M., and Miyaki, K.: VLF/LF sounding of the lower ionosphere to study the role of atmospheric oscillationsin the lithosphere-ionosphere coupling, Adv. Polar Upper Atmos. Res., 15, 146-158, 2001.

Molchanov, O. A.: On the origin of low- and middle-latitude ionospheric turbulence, Phys. Chem. Earth, 29(4-9) 559-567, 2004.

Molchanov, O. and Hayakawa, M.: Seismo-electromagnetics and related phenomena: History and latest results, TERRUPUB, pp. 432, 2007.

Nekrasov, A. K., Shalimov, S. L., Shukla, P. K., and Stenflo, L.: Nonlinear disturbances in the ionosphere due to acoustic gravity waves, J. Atmos. Terr. Phys., 57, 732-742, 1995.

Rozhnoi, A., Solovieva, M. S., Molchanov, O. A., and Hayakawa, M.: Middle latitude LF $(40 \mathrm{kHz})$ phase variations associated with earthquakes for quiet and disturbed geomagnetic conditions, Phys. Chem. Earth, 29, 589-598, 2004.

Rozhnoi, A. A., Solovieva, M. S., Molchanov, O. A., Hayakawa, M., Maekawa, S., and Biagi, P. F.: Anomalies of LF signal during seismic activity in November-December 2004, Nat. Hazards Earth Syst. Sci., 5, 1-4, 2005, http://www.nat-hazards-earth-syst-sci.net/5/1/2005/.

Rozhnoi, A. A., Solovieva, M. S., Molchanov, O. A., Hayakawa, M., Maekawa, S., and Biagi, P. F.: Sensitivity of LF signal to global ionosphere and atmosphere perturbations in the network of stations, Phys. Chem. Earth, 31, 409-415, 2006.

Rozhnoi, A., Molchanov, O., Solovieva, M., Gladyshev, V., Akentieva, O., Berthelier, J. J., Parrot, M., Lefeuvre, F., Biagi, P. F., Castellana, L., and Hayakawa, M.: Possible seismo-ionosphere perturbations revealed by VLF signals collected on ground and on a satellite, Nat. Hazards Earth Syst. Sci., 7, 617-624, 2007, http://www.nat-hazards-earth-syst-sci.net/7/617/2007/. 